(D) https://orcid.org/0000-0002-8202-4043

Военный институт ЖДВ и ВОСО

Кафедра русского языка

198504, Петергоф

ул. Суворовская, 1

assoben52@mail.ru

\title{
ЛЮБОВЬ, ГЕНДЕРНЫЕ РОЛИ И СТЕРЕОТИПЫ В РАССКАЗАХ АНТОНА ЧЕХОВА ИЗ НАРОДНОЙ ЖИЗНИ (АГАФЬЯ, БАБЫ)
}

\author{
LOVE, GENDER ROLES AND STEREOTYPES \\ IN CHEKHOV'S STORIES FROM PEASANTS' LIFE \\ (“AGAFYA", "BABY")
}

The article is devoted to Chekhov's stories from the life of peasants and explores how Chekhov described folk ideas about love, how he depicted gender roles and stereotypes prevalent in this environment. The short stories "Agafya" (1886) and "Baby" ("Peasant Wives") (1891) are interesting from the point of view of describing the state of a woman in love, her role in marriage and her social lot. Chekhov is sensitive to the framework of the folk culture, as reflected in 'Proverbs and Sayings of the Russian People' collected by Vladimir Dal. It is marked by male dominance, male aggression, dependent position of a woman, her vulnerability. Young girls shown in "Agafya" and "Peasant Wives" have been married off without love, and female sexuality finds its expression in extramarital relationships. In "Agafya" Savka attracts women with masculine beauty and an artistic manner. His contemplation, "concentrated immobility" and his love for birds are signs of inner freedom: Savka is not like everyone else. His existential choice arouses sympathy in women so that they bring him food or make dates with him at night. In the time of the story, Agafya has been a wife for a year, and the fact that she goes out on a date at night indirectly reflects on her marriage with a railway switchman. She will be punished in the morning.

In the short story "Peasant Wives" Mashenka also becomes a victim of male sexuality. When her husband had been conscripted and "packed off to Poland," a neighbour, Matvey Savvich, began to call on the young woman and to help her with the harder household work. In his own interpretation, "a year had not passed before the Evil One, the enemy of all mankind, confounded me" [from Constance Garnett's translation]. In Chekhov's text, the male character does not admit his guilt in seducing another man's wife; he puts the blame on the woman. Thus, he does not perform the main gender role of a man - to be the protector of his beloved. In Chekhov's short story there are two gender motives that explain a woman's love: the first is male help with the household; the second is women's loneliness, the need for contact and men's affection. In Matvey Savvich's description Masha is an adulteress and a criminal. And in all subsequent events - the wife getting bitten by her returned husband, his death from poisoning - Matvey takes the side of the formal justice. 
Chekhov's short stories are anti-literary in that they reveal the author's purpose as depicting peasant and burgher life as actual existence. There is no aestheticisation, heroisation or idealisation of peasant life, which were the sins of the populist writers (narodniki). Chekhov's Agafya and Mashenka are Russian women, their fates are typical both in terms of gender sociology and of gender psychology. Behind the complex narrative structure, the biographical author (Chekhov) hides his own feeling of pity and compassion for a specific female fate.

Keywords: love, stereotype, role, peasants, gender psychology.

Статья посвящена рассказам Чехова из народной жизни, тому, как Чехов описал народные представления о любви, обрисовал гендерные роли и стереотипы в этой среде. Рассказы Агафъя (1886) и Бабы (1891) интересны описанием состояния влюбленной женщины, ее роли в браке, ее социальной судьбы. Чехов чуток к рамкам народной культуры, которые можно найти в Пословищах и поговорках русского народа Вл. И. Даля: мужское доминирование, мужская агрессивность, зависимое положение женщины, ее бесправие. В Агафье и в Бабах молодых девушек выдали замуж без любви, и женская сексуальность проявляется в отношениях с мужчинами вне брака. Савка в Агафбе привлекает женщин мужской красотой и артистичностью. Его созерцательность, «сосредоточенная неподвижность», любовь к птицам - признаки внутренней свободы, он не такой, как все. И женщины «жалеют» его за этот экзистенциальный выбор, носят еду, приходят ночью на свидание. Агафью выдали замуж «год назад», и то, что она ночью приходит на свидание, - косвенная характеристика ее брака с железнодорожным стрелочником. Утром ее ждет расправа.

В рассказе Бабы Машенька тоже становится жертвой мужской сексуальности. Когда мужу «забрили лоб» и «погнали в Царство Польское», Матвей Саввич, сосед молодой женщины, стал к ней захаживать, помогать по хозяйству. В его интерпретации «не прошло и года, как смутил меня нечистый дух, враг рода человеческого». У Чехова герой не признает своей вины, что он соблазнил чужую жену; вину он перекладывает на женщину. Тем самым он не выполняет главную гендерную роль мужчины - быть защитником любимой женщины. В рассказе Чехова два гендерных мотива, поясняющих любовь женщины: первый - мужская помощь по хозяйству; второй мотив - женское одиночество, потребность в общении, в мужской ласке. В описании Матвея Саввича - Маша прелюбодейка и преступница. И во всех дальнейших событиях - избиении жены мужем, вернувшимся со службы, его смерти от отравления - он принимает сторону формального правосудия.

Рассказы Чехова антилитературны, т. е. в них обнаруживается установка автора на изображение крестьянской и мещанской жизни как экзистенции. В них нет эстетизации, героизации или идеализации мужицкой жизни, чем грешили писатели-народники. Агафья и Машенька у Чехова - русские женщины, их судьбы типичны и в аспекте гендерной социологии, и в аспекте гендерной психологии. За сложной повествовательной структурой биографический автор (Чехов) скрывает собственное чувство жалости и сострадания к конкретной женской судьбе.

Ключевые слова: любовь, стереотип, роль, народ, гендерная психология.

В 70-80-е гг. XIX в. появляется общественный интерес к проблеме женской эмансипации, в это время формируются и новые специализации в психологии и социологии (гендерная психология, гендерная социология). Вопросы пола выходят на первое место ${ }^{1}$. А. Штейнберг справедливо заметил:

${ }^{1}$ П. Е Астафьев, Психический мир женщины, его особенности, превосходства и недостатки, Москва: Университетская тип. (М. Катков) 1881; П. Е Астафьев, Понятие психического ритма как научное основание психологии полов, Москва: Университетская тип. (М. Катков) 
Сторонники феминизма должны были поставить под сомнение историческую и культурную неизменность в положении мужчин и женщин, конкретизировать «природное предназначение» мужчины и женщины. И они это сделали, разведя понятия биологического пола и социально-культурного пола, введя для обозначения последнего термин «гендер»².

Естественно, литература не могла остаться в стороне от этого процесса. Большим успехом пользовались роман Л. Н. Толстого Анна Каренина, повесть Крейцерова соната. Женщина, положение женщины в обществе, психология любви и брака были в центре внимания не только писателей первого, но и «второго ряда»: И. Ясинского, И. Потапенко, Н. Златовратского и др. Чехов, конечно же, не мог остаться в стороне от этого процесса. В письме к брату Александру в 1883 г. Чехов признавался:

Я разрабатываю теперь и в будущем разрабатывать буду один маленький вопрос: женский. Но, прежде всего, не смейся. Я ставлю его на естественную почву и сооружаю: «Историю полового авторитета» ${ }^{3}$.

Научный труд Чехов не написал, но в рассказах Поцелуй, Именины, Тина и в других произведениях немало верных наблюдений над мужской и женской психологией. В настоящей статье нас будут интересовать народная жизнь в изображении Чехова и то, как писатель воплотил в двух рассказах представления о любви в крестьянской и мещанской среде. По мнению А. С. Суворина, в русской истории особого угнетения женщины не было:

Русская женщина среднего и низшего состояния пользовалась обычной свободой и принимала участие в работе и заботах своего мужа. Что ей были знакомы чувства любви, даже и некоторого романтизма в любви - доказывают наши народные песни ${ }^{4}$.

1882; А. Шкляревский, Об отличительных свойствах мужского и женского типов в приложении к вопросу о высшем образовании женщин. Речь, произнесённая на торжественном акте университета Св. Владимира 9 января 1874 года профессором медицинской физики, Киев 1874; Л. О. Даркшевич, Об интеллектуальной сфере женщины, «Вопросы философии и психологии» 1895, № 1-5, кн. 26, с. 1-19; Е. Дюринг, Любовь и половая жизнь, Москва 1898; Ж. Мишле, Любовь и женщина, Санкт-Петербург: Calmann-Levy 1900; О. Вейнингер, Пол и характер, Москва 1902 и др.

${ }^{2}$ А. Г. Штейнберг, Женственность: не основной вопрос философии, Хабаровск: Изд-во ДВГУПС 2011, с. 83.

${ }^{3}$ Здесь и далее чеховские цитаты приводятся по изданию: А. П. Чехов, Полное собрание сочинений и писем: в 30 т., Москва: Наука 1973-1984. При цитатах в скобках указывается том и страница.

${ }^{4}$ А. С. Суворин, Очерк истории русской женщины, «Новое время» 1890, № 5106, 18 мая. 
Но так ли это?

В Толковом словаре живого великорусского языка В. И. Даля дается такое толкование слова «любовь»:

ж. об. (црк. любы, род. любве) - состояние любящего, страсть сердечная привязанность, склонность; вожделение; охота, расположение к чему5.

В Пословииах и поговорках русского народа отражена нелегкая доля женщины из народа, ее любовь, ее судьба: «Баба - не квашня: встала да и пошла», «молодица у старика - ни девка, ни баба, ни вдова», «жена мелет, а муж спит», «за плохим жить, только век должить» и др. Отражены в них и гендерные стереотипы: «Курице не быть петухом, а бабе мужиком», «кто с бабой свяжется - сам баба будет», «баба, что мешок: что положишь, то и несет» и др. ${ }^{6}$ Рассказы Агафья (1886) и Бабы (1891) интересны описанием состояния влюбленной женщины, ее роли в браке, ее социальной судьбы.

В Агаøье (1886) повествователь становится свидетелем свидания огородника Савки с чужой женой. Мы помним об одном из главных постулатов гендерной психологии - для женщины важен или социальный статус мужчины, или его личный статус ${ }^{7}$. Под личным статусом понимается принцип «твердости», внутренняя свобода, бытийная существенность, в которой имеет значение и мужская красота. Савка - крестьянский вариант Дон Жуана, только он не субъект, а объект поклонения: женщины сами «просятся» прийти к нему ночью. Рассказчик так описывает героя:

Савка был парень лет 25, рослый, красивый, здоровый, как кремень. Слыл он за человека рассудительного и толкового, был грамотен, водку пил редко, но как работник этот молодой и сильный человек не стоил и гроша медного (т. 5, с. 25).

Его созерцательность, «сосредоточенная неподвижность», любовь к птицам - признаки внутренней свободы, он не такой, как все. «От всей его фигуры так и веяло безмятежностью, врожденной, почти артистической страсти к житью зря, спустя рукава» (там же).

И женщины «жалеют» его за этот экзистенциальный выбор, носят еду, приходят ночью на свидание. «Кроме счастливой наружности и своеобразной

${ }^{5}$ В. И. Даль, Толковый словарь живого великорусского языка: в 4 т., Москва: АстрельACT 2001, т. 2, с. 459.

${ }^{6}$ В. И. Даль, Пословицы и поговорки русского народа, Москва: Вече 2006, с. 99-109.

${ }^{7}$ См.: Ш. Берн, Гендерная психология. Законы мужского и женского поведения, пер.: С. Рысев и др. Санкт-Петербург: Прайм-Еврознак 2007, с. 177. 
манеры обращения, надо думать, имела влияние на женщин также еще и трогательная роль Савки как всеми признанного неудачника и несчастного изгнанника из родной избы в огороды», - отмечает рассказчик (т. 5 , с. 32$)$.

Но рассказчик даже «привскочил от удивления», узнав, что этой ночью «просилась» Агафья Стрельчиха, «еще молодая бабенка лет 19-20, не далее как год тому назад вышедшая замуж за железнодорожного стрелочника, молодого и бравого парня» (т. 5, с. 28). Агафья всего год живет с мужем, и то, что она идет ночью на свидание, - косвенная характеристика семейной жизни женщины. Она неопытна в любовных делах, боится: «Увидев возле шалаша вместо одного двоих, она слабо вскрикнула и отступила шаг назад» (т. 5, с. 29). Героиня пытается соблюдать «приличия»: «Кланялся вам Яков и велел передать... вот тут что-то такое...» (там же).

Савка же лишен эмпатии, он не чувствует состояния женщины, не думает о том, что ей нужно вернуться в избу к определенному часу. Он «срывается», бежит ловить соловья, т. е. подчиняется инстинкту мужчины-охотника. В ночном свидании важен мотив опьянения: Савка дает Агафье выпить водки, женщина,

опьяненная водкой, презрительной лаской Савки и духотою ночи, лежала возле него на земле и судорожно прижималась лицом к его колену. Она так далеко ушла в чувство, что и не заметила моего прихода (т. 5, с. 32).

Современник Чехова писал: «Под влиянием сильных ощущений здравый взгляд на вещи у нее (женщины) еще больше затемняется нежели у мужчины» ${ }^{8}$. Агафья несомненно переживает «сильные ощущения», повидимому в семейной жизни она лишена их. И действительно, она забывает про необходимость «здравого взгляда на вещи». Муж ищет жену, а «с огородов слышался в это время несдерживаемый смех: жена забылась, опьянела и счастием нескольких часов старалась наверстать ожидавшую ее назавтра муку» (т. 5, с. 33). Финал у Чехова открытый: героиня переходит реку, ее «будто корчило от взглядов мужа». Но «Агафья вдруг вскочила, мотнула головой и смелой походкой направилась к мужу. Она, видимо, собралась с силами и решилась» (т. 5, с. 34). Читатель может только догадываться, что ожидает женщину.

В рассказе Бабы (1891) героиня тоже становится жертвой мужской сексуальности. Уже современники Чехова заметили, что в центре рассказа

${ }^{8}$ Дж. Патрик, Психология женщины при свете новых фактов и теорий, пер. с пол. Н. д’А, Санкт-Петербург: Ф. И. Митюрников 1900, с. 20. 
находятся вопросы пола в народной среде. А. П. Чудаков, автор комментариев, приводит цитату из письма И. И. Горбунова-Посадова А. М. Хирьякову. Горбунов-Посадов спрашивал: «Читал ли в „Новом времени” рассказ Чехова из народной жизни (половые драмы)» (т. 7, с. 685). В центре - история Машеньки в восприятии нарратора, рассказчика Матвея Саввича, его слушателей. М. Л. Семанова заметила: «На пересечении этих различных точек зрения и оценок выявляется авторское понимание вещей» ${ }^{9}$ Каково же «авторское понимание» любви и брака в народной среде? Собственно говоря, история в Бабах «начинается с того, что хозяин постоялого двора заинтересовался Кузькой, а проезжий стал рассказывать, откуда тот “у него взялся"» ${ }^{10}$.

Из рассказа Матвея Саввича слушатели (и читатели) узнают историю Машеньки, которую выдали замуж за нелюбимого. Сватовство ничем не отличалось от многих других:

Позвали сейчас сваху, пятое-десятое, бабьи разговоры, и пошел наш Вася невест глядеть. Засватал он у вдовы Самохвалики Машеньку. Недолго думающи, благословили и в одну неделю все дело оборудовали (т. 7, с. 343).

О таких браках народ говорил: «Крестом любви не свяжешь». Мужу вскоре «забрили лоб и погнали в Царство Польское». Машенька была «девочка молодая, лет семнадцати, маленькая, кургузенькая, но лицом белая и приятная, со всеми качествами, как барышня» (там же). Рассказчик был соседом молодой женщины, он стал к ней захаживать, помогать по хозяйству. В его интерпретации «не прошло и года, как смутил меня нечистый дух, враг рода человеческого» (там же). У Чехова герой, соблазнивший чужую жену, не признает своей вины, перекладывая ее на женщину:

Не только мы, грешные, но и святые мужи совращались. Машенька меня от себя не отвадила. Вместо того, чтобы мужа помнить и себя соблюдать, она меня полюбила - говорит он (т. 7, с. 344).

Тем самым он не выполняет главную гендерную роль мужчины - быть защитником любимой женщины. Муж Маши Вася «голубей породистых разводил», и когда с женой прощался, то - «ничего, а как взглянул последний раз на сенник с голубями, залился ручьем» (т. 7, с. 343). Однако голуби - занятие для детей, а не для мужчины. В глазах молодой и одинокой

${ }^{9}$ М. Л. Семанова, Чехов - художник, Москва: Просвещение 1976, с. 64.

${ }^{10}$ А. П. Чудаков, Мир Чехова. Возникновение и утверждение. Москва: Советский писатель 1986, с. 235. 
женщины личный и социальный статус Матвея Саввича был выше, чем у мужа (так ей казалось). В рассказе Чехова два гендерных мотива, поясняющих любовь женщины: первый - мужская помощь по хозяйству («Пять ломовых мужиков, народ все пьяный, озорной; лошади, дроги, там, гляди, забор обвалился или в трубе сажа загорелась - не женского ума дело»); второй мотив - женское одиночество, потребность в общении, в мужской ласке («Известное дело, не без того, зайдешь в дом, чаю выпьешь, поговоришь») (т. 7, с. 343). Соблазнение происходит на Святой неделе в ситуации бытовой, прозаической. Героиня кормила уток.

Я не удержался и окликнул. Она подошла и глядит на меня сквозь решетку. Личико белое, глазки ласковые, заспанные... Очень она мне понравилась, и стал я ей комплименты говорить, словно мы не у ворот, а на именинах, а она покраснела, смеется и все смотрит мне в самые глаза и не мигает. Потерял я разум и начал объяснять ей свои любовные чувства... Она отперла калитку, впустила, и с того утра стали мы жить, как муж и жена (т. 7, с. 343).

В описании Матвея Саввича Маша - прелюбодейка и преступница. И во всех дальнейших событиях - избиении жены мужем, вернувшимся со службы, его смерти от отравления - он принимает сторону формального правосудия. Мужчина стращает женщину, которую соблазнил, прячется за церковный авторитет: «Праведные, говорю, на том свете пойдут в рай, а ты в геенну огненную, заодно со всеми блудницами» (т. 7, с. 347). Поведение Матвея Саввича и его речи - это мужское доминирование, ярко выраженный гендерный стереотип. Он все время ссылается на авторитет Священного Писания, на Бога Отца, но забывает про Бога Сына:

Кто исповедует, что Иисус есть сын Божий, в том пребывает Бог, и он в Боге И мы познали любовь, которую имеет к нам Бог, и уверовали в нее. Бог есть любовь, и пребывающий в любви пребывает в Боге, и Бог в нем (1 Ин. 4, 15-16).

На суде одни «говорили, что она мужа отравила, а другие доказывали, что муж сам с горя отравился» (там же). Читатель помнит, что в пересказе Матвея Саввича эта версия тоже имела право на существование: «Вася сидит в другой комнате, держится за голову и плачет: „Злодей я! Погубил я свою жизнь! Пошли, мне господи, смерть” (там же). Таким образом, факт убийства мужа не был доказан, но Матвей Саввич, привлеченный судом в качестве свидетеля, дал обвинительные показания, и Машу сослали в Сибирь на 13 лет. По дороге она заболела и умерла. 


\section{В Острове Сахалине Чехов писал о женщинах-преступницах:}

это в большинстве женщины с темпераментом, осужденные за преступления романического и семейного характера: «за мужа пришла», «за свекровь пришла»... Это все больше убийцы, жертвы любви и семейного деспотизма (т. 13-14, с. 246) ${ }^{11}$.

Такой жертвой любви и семейного деспотизма и стала героиня рассказа. Могла ли она развестись с мужем? Вот что говорил закон:

Брак может быть расторгнут только формальным духовным судом: 1) в случае доказанного прелюбодеяния другого супруга, или неспособности его к брачному сожитию; 2) в случае, когда другой супруг приговорен к наказанию, сопряженному с лишением всех прав состояния; 3) в случае безвестного отсутствия другого супруга ${ }^{12}$.

Героиня Чехова под эту статью не подпадает, муж ей не изменял. В Бабах есть еще два женских характера. У Дюди - два сына: старший Федор служит на заводе, у него есть жена Софья, «некрасивая и болезненная баба». Второй сын, «горбатенький Алешка», пьяница, но его женили на красавице Варваре, «которую взяли из бедной семьи; это баба молодая, красивая, здоровая и щеголиха» (т. 7, с. 340). Эти женщины тоже несчастны в браке. Варвара «гуляет» с молодым поповичем. Она говорит Софье:

А пускай... Чего жалеть? Грех, так грех, а лучше пускай гром убьет, чем такая жизнь. Я молодая, здоровая, а муж у меня горбатый, постылый, крутой, хуже Дюди проклятого. В девках жила, куска не доедала, босая ходила и ушла от тех злыдней, польстилась на Алешкино богатство и попала в неволю, как рыба в вершу, и легче мне было бы с гадюкой спать, чем с этим Алешкой паршивым. А твоя жизнь? Не глядели 6 мои глаза. Твой Федор прогнал тебя с завода к отцу, а сам себе другую завел; мальчишку у тебя отняли и в неволю отдали. Работаешь ты, словно лошадь, и доброго слова не слышишь. Лучше весь свой век в девках маяться, лучше с поповичей полтинники брать, милостыню собирать, лучше в колодезь головой... (т. 7, с. 350).

Когда женщины ложатся спать, Варвара признается Софье: «Я бы своего Алешку извела и не пожалела» (т. 7, с. 351). А. М. Турков писал: «Поразительно,

${ }^{11}$ Г. А. Бялый заметил: «В книге Остров Сахалин Чехов выступил не как художник, не как публицист, а как исследователь народной жизни, протекающей в условиях каторги и ссылки». См.: Г. А. Бялый, Русский реализм. От Тургенева к Чехову, Ленинград: Советский писатель 1990, с. 272. Рассказ Бабы, несомненно, имеет отношение к Острову Сахалину и по материалу, и по «точке зрения» повествователя.

${ }^{12}$ См.: «Женский вестник» 1905, № 2, с. 51. 
что религиозная Софья не открещивается от ужасного предложения, а, видимо, всерьез взвешивает его. И хотя Варвара тут же винится, что говорит, себя не помня, но знаменательна уже сама возможность такого разговора, таких мыслей» ${ }^{13}$. Но идея «извести» мужей остается ночной фантазией героини. Утро начинается с бытовых забот: «Раньше всех проснулась старуха. Она разбудила Софью, и обе пошли под навес доить коров» (т. 7, с. 351).

Любовная история, рассказанная Матвеем Саввичем, начинается с Кузьки, им и заканчивается. Ребенок не знает, где его шапка: «Я тебе уши оборву! - крикнул Матвей Саввич. - Поганец этакий». Шапка нашлась на дне повозки. «Кузька рукавом стряхнул с нее сено, надел и робко, все еще с выражением ужаса на лице, точно боясь, чтобы его не ударили сзади, полез в повозку» (т. 7, с. 352). Этот эпизод - последний штрих в характеристике рассказчика. Шапка - всего лишь бытовая подробность, ее функция «рисовать жизнь, по выражению Чехова, «как она есть» ${ }^{14}$.

Рассказы Чехова «антилитературны», т. е. в них обнаруживается установка автора на изображение крестьянской и мещанской жизни как экзистенции. Естественно, это тоже «литература», но на иных эстетических принципах. В письмах Чехова, когда он работал еще над Ивановым и Лешим, появились определения - «живая жизнь» и «живые люди». В Агафье и в Бабах автора интересует не столько «крестьянская» или «мещанская» любовь, сколько «голый человек» в жизни-экзистенции. В рассказах Чехова нет также эстетизации, героизации или идеализации мужицкой жизни, чем грешили писатели-народники. Так, например, Н. Н. Златовратский восхищался крестьянками:

[...] я долго молча наблюдал за ними, всматриваясь в их грубые, загорелые лица, в их мерные, медленные движения, когда они таскали на спинах трех-четырехпудовые мешки. Я вслушивался в их тягучую, размеренную, вежливую, но неподобострастную речь, когда они говорили с моим отцом. Из своих наблюдений прежде всего я вывел одно: что эти женщины не были женщины, как я представлял их по окружавшим меня, что они если и женщины, то совершенно «особенные», как, например, совершенно особенными представлялись мне женщины Новой Гвинеи или Африки, которых я рассматривал в Живописном обозрении ${ }^{15}$.

Агафья и Машенька у Чехова - русские женщины, их судьбы типичны и в аспекте гендерной социологии, и в аспекте гендерной психологии. За сложной повествовательной структурой биографический автор (Чехов)

${ }^{13}$ А. М. Турков, А. П. Чехов и его время, Москва: Художественная литература 1980, с. 159.

${ }^{14}$ А. П. Чудаков, Мир Чехова..., с. 166.

${ }^{15}$ Н. Н. Златовратский, Золотые сердиз, [в:] Собрание сочинений: в 3 т., Москва: Типо-лит т-ва И. Н. Кушнарев и К 1897, т. 3, с. 48. 
скрывает собственное чувство жалости и сострадания к конкретной женской судьбе. «Мы, женщины, гордимся таким печальником и защитником», - писал автор статьи Чехов о женщинах ${ }^{16}$.

\section{References}

Astafev, Petr E. Ponyatie psikhicheskogo ritma kak nauchnoe osnovanie psikhologii polov. Moskva: Universitetskaya tip. (M. Katkov), 1882.

Astafev, Petr E. Psikhicheskii mir zhenshchiny, ego osobennosti, prevoskhodstva i nedostatki. Moskva: Universitetskaya tip. (M. Katkov), 1881.

Bern, Shon. Gendernaya psikhologiya. Zakony muzhskogo i zhenskogo povedeniya. Sankt-Peterburg: Praim EVROZNAK, 2007.

Bl-va, M. “Chekhov o zhenshchinakh". Zhenskii vestnik. No. 2 (1905): 44-45.

Byalyi, Grigorii A. Russkii realizm. Ot Turgeneva k Chekhovu. Leningrad: Sovetskii pisatel, 1990.

Chekhov, Anton P. Polnoe sobranie sochinenii i pisem: v 30 t. Moskva: Nauka, 1973-1984.

Chudakov, Aleksandr P. Mir Chekhova. Vozniknovenie i utverzhdenie. Moskva: Sovetskii pisatel, 1986.

Dal, Vladimir I. Poslovitsy i pogovorki russkogo naroda. Moskva: Veche, 2006: 304.

Dal, Vladimir I. Tolkovyi slovar zhivogo velikorusskogo yazyka: v 4 t. Vol. 2. Moskva: Astrel-AST, 2001: 1280 .

Darkshevich, Liverii O. “Ob intellektualnoi sfere zhenshchiny”. Voprosy filosofii i psikhologii, No. 1-5 (1895): 1-19.

Dyuring, Evgeni. Lyubov i polovaya zhizn. Moskva, 1898.

Mishle, Zhyul. Lyubov i zhenshchina. Sankt-Peterburg: Calmann-Levy, 1900.

Patrik, Dzhordzh. Psikhologiya zhenshchiny pri svete novykh faktov i teorii. Sankt-Peterburg, 1900.

Semanova, Mariya L. Chekhov - khudozhnik. Moskva: Prosveshchenie, 1976.

Shteynberg, Aleksei G. Zhenstvennost: ne osnovnoi vopros filosofii. Khabarovsk: Izd-vo DVGUPS, 2011. Turkov, Andrei M. A. P. Chekhov i ego vremya. Moskva: Khudozhestvennaya literatura, 1980.

Veyninger, Otto. Pol i kharakter, Moskva, 1902.

Zlatovratskii, Nikolai N. Zolotye serdtsa. In: Zlatovratskii, Nikolai N. Sobranie sochinienii: v 3 t. Vol. 3. Moskva, 1897: 350.

\footnotetext{
@creative

(C) by the author, licensee Lodz University - Lodz University Press, Lodz, Poland. This article is an open access article distributed under the terms and conditions of the Creative Commons Attribution license CC-BY-NC-ND 4.0 (https://creativecommons.org/licenses/by-nc-nd/4.0/)
}

${ }^{16}$ М. Бл-ва, Чехов о женщинах, «Женский вестник» 1905, №2, с. 45. 